\section{Hepatocellular Carcinoma with Macrovascular Invasion: Defining the Optimal Treatment Strategy}

\author{
Charlotte E. Costentin $^{a} \quad$ Cristina R. Ferrone $^{b}$ Ronald S. Arellano ${ }^{c}$ \\ Suvranu Gangulic Theodore S. Hong ${ }^{d}$ Andrew X. Zhu ${ }^{\text {a }}$ \\ a Massachusetts General Hospital Cancer Center, Harvard Medical School, Departments of \\ bSurgery and ' Radiology, Massachusetts General Hospital, Harvard Medical School, and \\ dDepartment of Radiation Oncology, Massachusetts General Hospital, Boston, MA, USA
}

\section{Keywords}

Hepatocellular carcinoma $\cdot$ Macrovascular invasion $\cdot$ Sorafenib alternatives

\begin{abstract}
Background: Tumoral macrovascular invasion (MVI) of hepatic and/or portal vein branches is a common phenomenon in hepatocellular carcinoma (HCC) and is associated with poorer prognosis when compared to HCC without MVI. Summary: Current international guidelines for the management of HCC recommend sorafenib as the only treatment option in case of MVI. Despite guideline recommendations, several alternative options have been tested to manage HCC with MVI: surgery, transarterial chemoembolization, external or internal radiation, hepatic arterial infusion chemotherapy, percutaneous treatment, cryotherapy, or the combination of two or more of these strategies, with or without sorafenib. Here we will provide a comprehensive state-of-the-art review for the management of this challenging clinical entity based on the most recent available data. Key Messages: There is a growing body of evidence suggesting that alternative strategies to standard-of-care sorafenib might improve survival in patients with advanced HCC with MVI but the level of evidence remains weak. Randomized phase III trials are ongoing and will hopefully provide information leading towards a more personalized treatment algorithm.

(c) 2017 S. Karger AG, Basel
\end{abstract}

Charlotte E. Costentin, MD and Andrew X. Zhu, MD, PhD

Massachusetts General Hospital Cancer Center

55 Fruit St

Boston, MA 02114 (USA)

E-Mail CLAURENTCOSTENTIN @ mgh.harvard.edu and AZHU@ mgh.harvard.edu 


\section{Introduction}

Tumoral macrovascular invasion (MVI) of hepatic and/or portal vein branches is common during the natural history of hepatocellular carcinoma (HCC) and significantly reduces median survival when compared to patients without MVI [1, 2]. Current international guidelines recommend sorafenib as the only treatment option in case of MVI [3-5]. Interestingly, the recently released American Association for the Study of Liver Diseases (AASLD) guidelines point out that the selection of treatment may vary depending on the extent of MVI [3]. Indeed, recent data suggest that HCC with MVI might benefit from locoregional therapies alone, or the combination of locoregional and systemic treatments. However, two phase III trials comparing selective internal radiation therapy to sorafenib (SAHAH and SIRveNIB trials) recently failed to meet their primary endpoint to improve survival $[6,7]$.

In this review, we will discuss survival expectations with standard-of-care sorafenib and the evolving promising alternative options. We will review the strengths and weaknesses of the most recent available studies and highlight the lessons learned. We will discuss ongoing clinical trials with advanced HCC, either those with MVI alone or those including MVI, which will be the cornerstones leading towards a more personalized treatment algorithm.

\section{Natural History}

MVI of hepatic and/or portal vein branches is present in about $10-40 \%$ of patients at diagnosis of HCC [1]. If present, it prevents listing for liver transplantation and classifies the cancer as advanced stage of HCC, leading to palliative treatment with poor prognosis $[1,2]$.

Of all types of MVI, portal vein tumor thrombus (PVTT) is more frequent than hepatic vein tumor thrombus (HVTT) and most available data regarding the natural history, diagnosis and treatment of patients with MVI are based on patients with PVTT. PVTT significantly reduces median survival (2-4 months) when compared to patients without PVTT (10-24 months) [8]. The extent of PVTT further impacts the prognosis: distal PVTT is usually associated with better survival than PVTT involving first-order branches or the main portal trunk [9]. Regarding HVTT, the involvement of the inferior vena cava seems to be a turning point, portending an even poorer prognosis [10].

\section{Diagnosis}

Cross-sectional imaging plays a vital role in the diagnosis of MVI, in particular contrast material-enhanced computed tomography (CT) or magnetic resonance imaging (MRI). The Liver Imaging Reporting and Data System (LiRADs v14) provides guidelines for PVTT diagnosis [11]. Tumoral thrombosis can generally be expected to follow enhancement characteristics similar to primary parenchymal HCC, when there is a definite soft tissue arterial enhancement not attributable to mixing artefacts and/or enlargement of the portal vein and/ or hepatic vein. While not diagnostic of tumor in the vein, the following features should alert clinicians to the possibility of tumor thrombus:

- occluded vein with expanded lumen, or ill-defined walls, or restricted diffusion on diffusion-weighted MRI sequences, or contiguous with typical HCC lesion;

- obscured, partially visualized vein;

- heterogeneous enhancement of vein not attributable to mixing artefact. 
By comparison, nontumoral thrombus does not enhance and usually does not expand the lumen. When standard imaging is controversial, contrast-enhanced ultrasound can provide additional clues to assess the nature of the thrombus. In a cohort of 50 patients, Rossi et al. [12] reported a $98 \%$ rate of correctly characterized tumor thrombi with CEUS, which outperformed CT in terms of both thrombus detection and characterization.

Positron emission tomography-computed tomography (PET-CT) was also shown to provide valuable information in this setting. Hu et al. [13] studied the performance of ${ }^{(18)}$ F-FDG PET-CT to confirm malignancy of portal vein thrombosis using 2 criteria: visual analysis and SUV max >3.35. ${ }^{(18)}$ F-FDG PET-CT results were confirmed with histopathological results, clinical, and imaging follow-up. The sensitivities, specificities, and accuracies for the two criteria were 91.5 and $93.6 \%, 64.0$ and $80.0 \%$, and 81.9 and $88.9 \%$, respectively [13].

When the diagnosis remains unclear with noninvasive techniques, needle biopsy of the thrombus under either ultrasound or CT guidance has been shown to be effective [14]. However, it remains an invasive technique and carries an increased risk in patients with underlying cirrhosis and coagulopathy. Therefore, the benefit/risk ratio should be carefully balanced before considering a biopsy.

\section{Classification}

The most conventional classification for PVTT is the classification proposed by the Liver Cancer Study Group of Japan, which divides PVTT into 4 classes according to the extent of the thrombus: Vp1 is defined by the presence of a PVTT distal to, but not in, the second-order branches of the portal vein; Vp2 is defined by the presence of a PVTT in the second-order branches of the portal vein; Vp3 is defined by the presence of a PVTT in the first-order branches of the portal vein; and Vp4 is defined by the presence of a PVTT in the main trunk of the portal vein or a contralateral portal vein branch or both (Fig. 1) [15].

HVTT was also categorized by the Japanese staging system in 3 categories: tumor thrombosis in a peripheral hepatic vein (pHVTT or Vv1), in a major hepatic vein (mHVTT or Vv2), or in the inferior vena cava (IVCTT or Vv3) [16].

\section{Treatment Guidelines}

International guidelines recommend sorafenib for advanced HCC with MVI, regardless of the extent of MVI [3-5]. According to the National Comprehensive Cancer Network (NCCN Guidelines version 2.2016) for HCC, in cases of extensive liver tumor burden, sorafenib, clinical trials, or best supportive care are the recommended options, depending on patient's general functional status and hepatic function [17]. The recently updated AASLD guidelines point out that the selection of treatment may vary depending on the extent of MVI, but still underlining that no recommendation could be made for systemic therapy over local regional therapy or a preferred type of local regional therapy based on the available evidence [3].

The two sorafenib registration trials are the only available level I evidence so far demonstrating an improved survival with an intervention treatment compared to best supportive care in advanced HCC, including patients with or without MVI $[2,18]$. Median overall survivals in the subgroup of patients with MVI are provided in exploratory subanalysis: 5.6-8.1 months with sorafenib compared to 4.1-4.9 with placebo $[19,20]$. To date, no large randomized controlled trials have provided evidence of survival over standard-of-care sorafenib in this setting. 


\section{cancer}

Costentin et al.: Hepatocellular Carcinoma with Macrovascular Invasion: Defining the Optimal Treatment Strategy

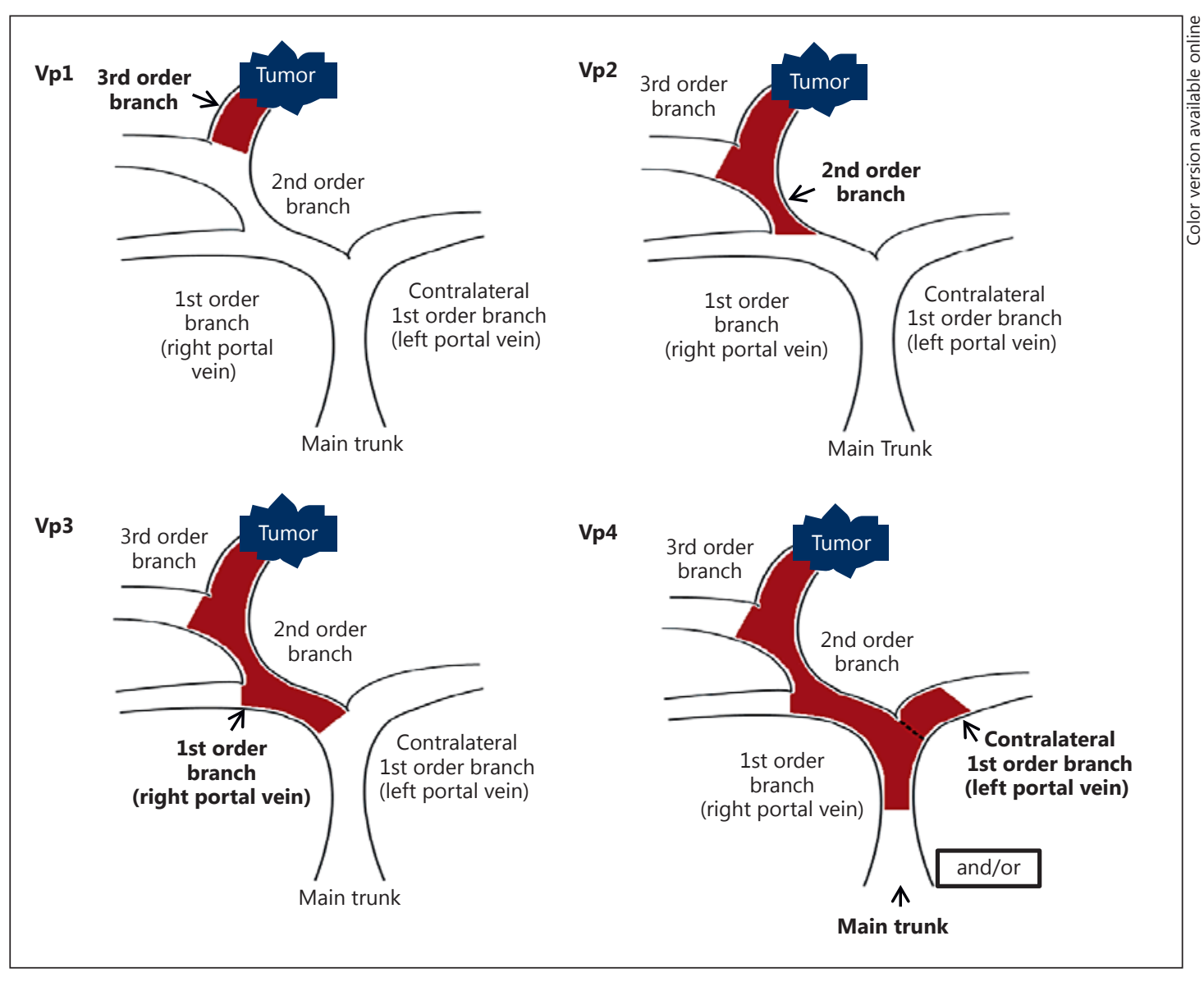

Fig. 1. Classification for hepatocellular carcinoma with portal vein tumor thrombosis according to the Liver Cancer Study Group of Japan classification.

\section{Alternative Treatment Strategies}

Despite guidelines recommending sorafenib as the standard treatment for HCC with any MVI, many studies suggest alternative or more aggressive treatment approaches could benefit selected patients.

\section{Surgical Resection}

A systematic review of 24 studies involving more than 4,000 patients with MVI showed that hepatic resection was associated with median overall survival rates of 50 and $18 \%$ at 1 and 5 years, respectively [21]. Recently, Kokudo et al. [10] reported survival of up to 3.95 years for resected tumors with major hepatic vein involvement, but sparing the inferior vena cava. In addition, in a large cohort of patients with HCC and PVTT, a study originating from the same group showed that patients who underwent hepatic resection had a significantly longer survival compared to patients treated with nonsurgical strategies ( 2.87 vs. 1.10 years) [9]. It is important to note that no survival benefit was observed for hepatic resection among patients with Vp4 PVTT. Based on these reports, some experts advocate for offering hepatic resection to patients with first-order branch PVTT and preserved liver function [22]. However, lack of comparison with current standard of care can be considered as a limitation to fully 
endorse and recommend hepatic resection in this setting. This raises the question of conducting a randomized controlled trial comparing resection with current standard-of-care sorafenib. Despite sorafenib being available in most countries since 2008, such trial has never been conducted. To date, there is only one study available comparing survival in patients treated with surgical resection or sorafenib in HCC patients with MVI using a propensity score matching [23]. Under the propensity analysis, the overall survival of patients with HCC and MVI undergoing surgical resection $(n=46)$ was similar to that achieved with sorafenib $(n=$ 39): 12.0 versus 9.7 months, respectively $(p=0.682)$.

\section{Transarterial Chemoembolization (TACE)}

Although TACE is traditionally not recommended for patients with PVTT $[3,4]$ due to the increased risk of liver failure, a retrospective observational single-center study compared TACE alone $(n=295)$, TACE with radiation $(n=196)$, and sorafenib alone $(n=66)$ in patients with advanced HCC with portal vein thrombosis. In the matching analysis comparing 46 pairs of patients treated with TACE alone or sorafenib alone, the TACE-alone group had longer median time to progression (3.4 vs. 1.8 months; $p<0.001$ ) and overall survival (5.9 vs. 4.4 months; $p=0.003$ ). However, the difference in terms of overall survival was not persistent with the inverse probability of treatment-weighted outcomes approach [24].

\section{Hepatic Arterial Infusion Chemotherapy (HAIC)}

In 2013, Nouso et al. [25] reported the result of a study assessing the effect of HAIC with 5 -fluorouracil and cisplatin for advanced HCC with or without MVI in the Nationwide Survey of Primary Liver Cancer in Japan. In a propensity score-matched analysis involving 682 patients, median survival time was longer for patients who underwent chemotherapy (14.0 months) than for patients who did not receive active treatment (5.2 months, $p<0.0001$ ) [25]. Compared with no therapy, HAIC improved survival, regardless of prognostic factors including MVI. More recently, Song et al. [26] retrospectively compared 50 patients treated with HAIC using cisplatin and 5-fluorouracil and 60 patients treated with sorafenib. In both groups, patients could receive additional locoregional treatments. The median overall survival was significantly longer in the HAIC group than in the sorafenib group (7.1 vs. 5.5 months, $p=$ 0.011). However, due to imbalance in additional locoregional treatments favoring the HAIC group, a subgroup analysis was performed on the group of 83 patients without combined locoregional treatment, showing no significant differences in overall survival (5.7 vs. 5.3 months, $p=0.214$ ) [26]. In addition, two studies compared HAIC and sorafenib in patients with advanced HCC using propensity score matching. Fukubayashi et al. [27] analyzed 72 patients treated with sorafenib and 128 patients receiving HAIC. In this study, more than $50 \%$ of the patients had vascular invasion. HAIC was implemented using two regimens: 102 patients were treated by the low-dose cisplatin +5 -fluorouracil regimen, and 26 were treated by the subcutaneous IFN- $\alpha+5$-fluorouracil regimen of HAIC. Analysis of 53 patients selected from each of the sorafenib and HAIC groups based on the propensity score-matching method showed no significant differences in survival ( $p=0.750)$ [27]. Shiozawa et al. [28] compared sorafenib versus HAIC with cisplatin and 5 -fluorouracil for in 80 patients with advanced HCC. Despite matching, more patients in the HAIC group had vascular invasion (40\%) compared to the sorafenib group (15\%) $(p=0.012)$ and no significant difference was noted in overall survival between both groups ( $p=0.56$ ) [28]. However, as patients with or without vascular invasion are pooled in these two studies, specific data in the population with vascular invasion are not easy to analyze. 


\section{Radiation}

External Radiation

External beam radiation therapy has undergone several modern advances, allowing for safe delivery of radiation to HCC with ablative doses. Radiation therapy is an attractive modality because it is not dependent on vasculature to access the tumor. Specifically, arterial embolism is relatively contraindicated in portal vein thrombus because of lack of hepatic inflow. Retrospective single-arm studies have studied radiation in treating HCC with PVTT reporting favorable toxicity profile and interesting efficacy results [29]. One study provides a direct comparison of external beam radiation therapy with sorafenib. Nakazawa et al. [30] retrospectively studied 97 patients: 40 receiving sorafenib and 57 receiving radiotherapy. After propensity score matching (28 patients in each group), patients treated with radiotherapy had a better survival compared to patients treated with sorafenib (median overall survival, 10.9 vs. 4.8 months; $p=0.025$ ). Radiotherapy was an independent factor associated with survival in multivariate analysis [30].

More recently, a prospective evaluation of stereotactic body radiotherapy (SBRT) in HCC conducted at Princess Margaret Hospital evaluated patients with unresectable HCC [31]. In this phase II study, 56 patients were treated to a median dose of 36 Gy (24-54 Gy range) in 6 fractions. Half of the patients had tumor vascular thrombosis. Overall, the patients had a one-year overall survival of 44\%, median survival of 10.6 months, with a local control of approximately $90 \%$ at 1 year.

High-dose proton therapy is another form of external beam radiation therapy, but has a distinct physical advantage over standard photon-based radiation therapy. While photons deposit dose beyond the tumor and through the patient, protons deposit energy at a prespecified depth without exit dose, providing a theoretical benefit of organ protection. The most favorable outcomes were seen in a series by the University of Tsukuba, Japan, which included 35 patients with HCC and tumor thrombi in the main trunk or major branches of the portal vein [32]. A median survival of 22 months and a median local progression-free survival of 21 months was observed after fractionated proton radiation to a median dose of 72.6 GyE in 2.2-5.5 GyE fractions. In a prospective phase II study of protons in primary liver tumors, 44 patients with HCC were treated with high-dose protons [33]. Median tumor size was $6 \mathrm{~cm}$, and one-third of the patients had macroscopic vascular invasion. Local control at 2 years was $95 \%$, with a 2-year overall survival of $63 \%$. The results of these prospective studies provide strong rationale for ongoing evaluation of radiation in the Radiation Therapy Oncology Group (RTOG) 1112 study, a phase III study evaluating the addition of SBRT to sorafenib versus sorafenib alone.

Selective Internal Radiation Therapy (SIRT)

Several retrospective series have reported the safety and efficacy of SIRT in patients with HCC with or without MVI [34]. Three studies including only patients with HCC and PVTT reported direct comparison of SIRT and sorafenib [35-37]. Cho et al. [35] evaluated 32 patients from a multicenter retrospective cohort. All patients had PVTT without extrahepatic spread and were treated with radioembolization and compared to 31 consecutive PVTT patients without extrahepatic spread who received sorafenib. No differences in overall survival ( $p=0.97$ ) was observed by propensity score analysis. The sorafenib group showed significantly more grade 3-4 adverse effects than the radioembolization group $(p<0.01)$.

de la Torre et al. [36] compared 26 patients with PVTT treated with radioembolization and 47 treated with sorafenib with comparable baseline characteristics. Median survival of 8.8 months in the radioembolization group and 5.4 months in the sorafenib group ( $p=0.047)$ was reported [36]. 
Edeline et al. [37] also found a difference in median overall survival with radioembolization versus sorafenib even after propensity analysis ( 26.2 vs. 8.7 months; $p=0.054$ ) in HCC with PVTT. Treatment with radioembolization was found to be associated with better overall survival (HR 0.40 [0.19-0.82]; $p=0.013$ ). Importantly, grade 3-4 adverse events were more frequent with sorafenib than with radioembolization (44.6 vs. 17.6\%) [37].

\section{Percutaneous Treatment}

Two retrospective studies reported 3-year survival rates of 22 and 77\% with percutaneous laser ablation (108 patients) and radiofrequency ablation (13 patients), respectively $[38,39]$. However, the lack of control arm prevents a relevant comparison with standard of care sorafenib.

\section{Multimodal or Combination Strategies}

Many retrospective studies reported interesting survival results with a wide variety of multimodal or combination strategies.

Multimodal Therapy Including Resection

Several combinations including resection have been tested (TACE before or after resection, infusion of postoperative intraportal chemotherapy, preoperative systemic chemotherapy, resection followed by external radiotherapy). Median survival reported in these series range from 13 to 22.1 months [40]. However, no study comparing multimodal therapy including surgical resection with standard-of-care sorafenib is available to date.

\section{TACE Combined with Sorafenib}

Two studies provide results with TACE combined with sorafenib in patients with advanced HCC and PVTT. Zhang et al. [41] retrospectively analyzed 45 patients treated with combination therapy and 45 patients treated with sorafenib monotherapy. Median overall survival was equivalent ( 7.0 and 6.0 months, respectively; $p=0.544$ ). Ha et al. [42] conducted a retrospective study including 658 patients with advanced HCC. Among the 257 patients with portal vein invasion, survivals with combination therapy (TACE plus sorafenib; 25.7 months) and TACE followed by sorafenib (14.0 months) were significantly longer than that with sorafenib monotherapy (5.5 months), regardless of the metastatic status at the time of sorafenib initiation. However, imbalance in patients' baseline characteristics is a concern to properly interpret these results.

HAIC Combined with Sorafenib

Ikeda et al. [43] recently published the results of a randomized phase II trial comparing sorafenib alone versus sorafenib plus HAIC with cisplatin in advanced HCC. A total of 108 patients with or without MVI were randomized to receive sorafenib $(n=42)$ or sorafenib plus HAIC with cisplatin $(n=66)$. The median survival was 8.7 months in the sorafenib-alone group and 10.6 months in the combination group ( $p=0.031$ ). In the prespecified subgroup analysis of overall survival, the combination treatment did not show better overall survival in case of PVTT ( 9.1 months), compared to sorafenib alone (7.1 months) ( $p=0.086$ ). Following these results, a phase III randomized trial comparing sorafenib alone with sorafenib plus HAIC using low-dose cisplatin and 5-fluorouracil has been conducted. Although not yet published, preliminary results were recently released [44]. The combination strategy did not significantly improve overall survival in the whole study population compared with sorafenib. However, in patients with main portal vein trunk invasion, the combination of sorafenib plus HAIC significantly improved overall survival (11.4 vs. 6.5 months; $p=0.034)$ compared with sorafenib alone. 
Multimodal Treatment Including Radiotherapy

In a retrospective study with propensity score analysis comparing the combination of TACE plus radiotherapy $(n=27)$ versus sorafenib $(n=27)$ in patients with HCC with MVI, overall survival in the TACE-plus-radiotherapy group was significantly prolonged (8.9 months) compared to the sorafenib group (3.1 months, $p<0.001$ ) [45].

Another retrospective observational single-center study compared TACE alone $(n=295)$ or TACE plus radiation $(n=196)$, and sorafenib alone $(n=66)$ in patients with advanced HCC with portal vein thrombosis. In the matching analysis comparing 30 pairs of patients treated with TACE plus radiation or sorafenib alone, the TACE-plus-radiation group had longer median time to progression (5.1 vs. 1.6 months; $p<0.001$ ) and overall survival (8.2 vs. 3.2 months; $p<0.001$ ) than the sorafenib-alone group, in agreement with the inverse probability of treatment-weighted outcomes [24].

Radiofrequency Combined with Sorafenib

In a randomized controlled trial, Giorgio et al. [46] compared patients with HCC and PVTT treated with sorafenib plus percutaneous radiofrequency ablation of both intraparenchymal HCC and PVTT versus sorafenib alone. Ninety-nine patients with Child A cirrhosis were included (49 in the combination group and 50 in the sorafenib-alone group). One-, 2-, and 3 -year survival rates were 60,35 , and $26 \%$, respectively, in the combination group and 37 and $0 \%$ at 1 and 2 years, respectively, in the sorafenib-alone group $(p<0.001)$. In multivariate analysis, the combination treatment was the only factor predicting survival.

Cryotherapy Combined with Sorafenib

One hundred four HCC patients were enrolled in a prospective study assessing the safety and efficacy of sorafenib plus cryotherapy in advanced HCC with portal vein thrombosis but without distant metastasis. Patients were randomly divided into sorafenib-cryotherapy and sorafenib groups. After a median follow-up of 10.5 (4-26) months, the data showed that median time to progression (primary endpoint) was 9.5 months in the combination therapy group versus 5.3 months in the sorafenib group $(p=0.02)$. The median overall survival was 12.5 months in the combination therapy group vs. 8.6 months in the sorafenib group $(p=$ 0.01 ) [47].

In light of all these reports, HCC with MVI might indeed be suitable for a strategy combining sorafenib and a locoregional treatment targeting the liver and the tumor thrombus. These combined treatments may potentially provide with better outcomes than sorafenib alone, a treatment with limited objective response rates. However, the body of evidence remains weak, and international guidelines did not endorse any alternative strategy yet. Most studies are retrospective, and the few randomized controlled studies providing positive results over sorafenib included a limited number of patients. Table 1 summarizes the results of all studies providing direct comparison between standard-of-care sorafenib and alternative strategies in the specific subgroup of HCC with MVI.

\section{Ongoing Research and Future Development}

Acknowledging that HCC with MVI but no extrahepatic spread is a unique clinical entity that deserves dedicated research, several teams have initiated clinical trials targeting this specific clinical setting. Ongoing phase III trials compare TACE to sorafenib, TheraSphere to sorafenib, and TACE and radiofrequency ablation versus TACE. An ongoing phase II trial compares sorafenib and HAIC to sorafenib, and several combination strategies will be tested (Table 2). 


\section{Liver \\ Cancer}

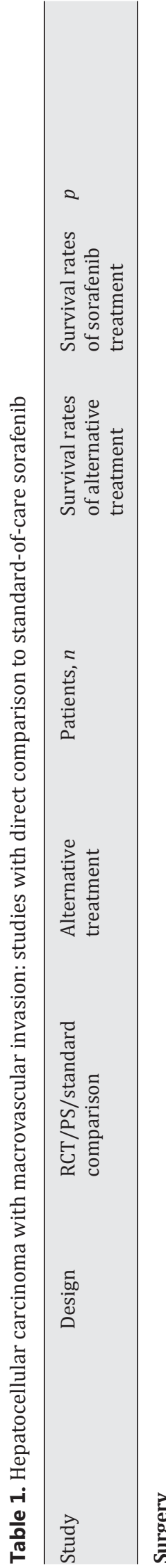

\begin{tabular}{l} 
Liver Cancer 2017;6:360-374 \\
\hline DOI: $10.1159 / 000481315$
\end{tabular}

(c) 2017 S. Karger AG, Basel www.karger.com/lic

Costentin et al.: Hepatocellular Carcinoma with Macrovascular Invasion: Defining the Optimal Treatment Strategy

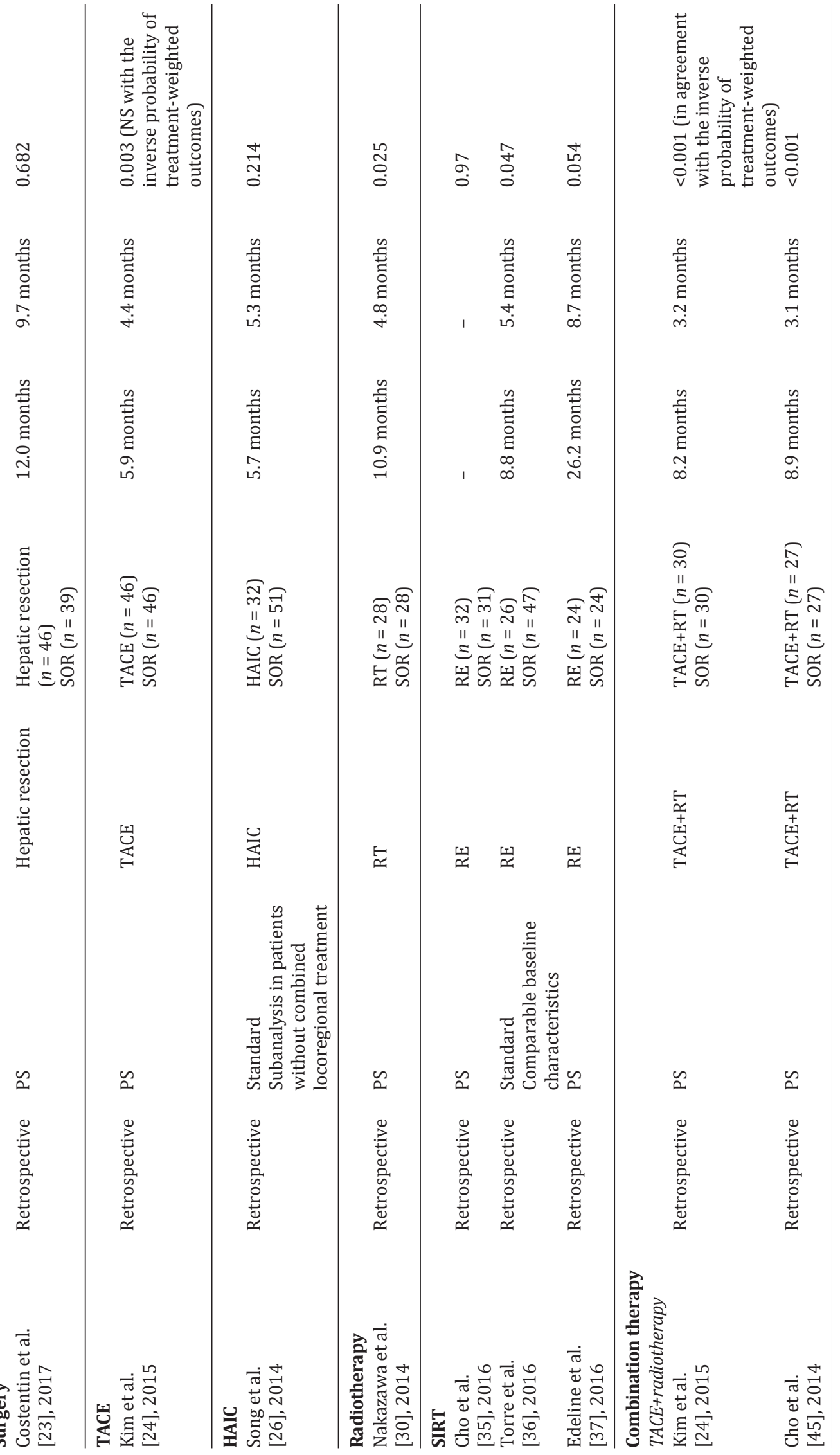




\section{Liver \\ Cancer}
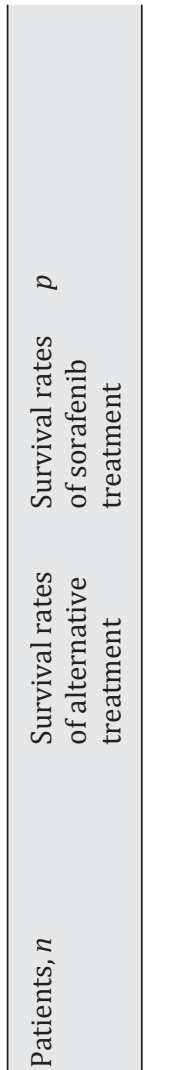

2

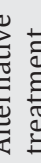

部

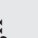

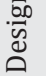

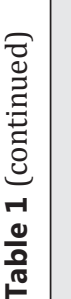

Liver Cancer 2017;6:360-374

DOI: $10.1159 / 000481315$

2017 S. Karger AG, Base

Costentin et al.: Hepatocellular Carcinoma with Macrovascular Invasion: Defining the Optimal Treatment Strategy

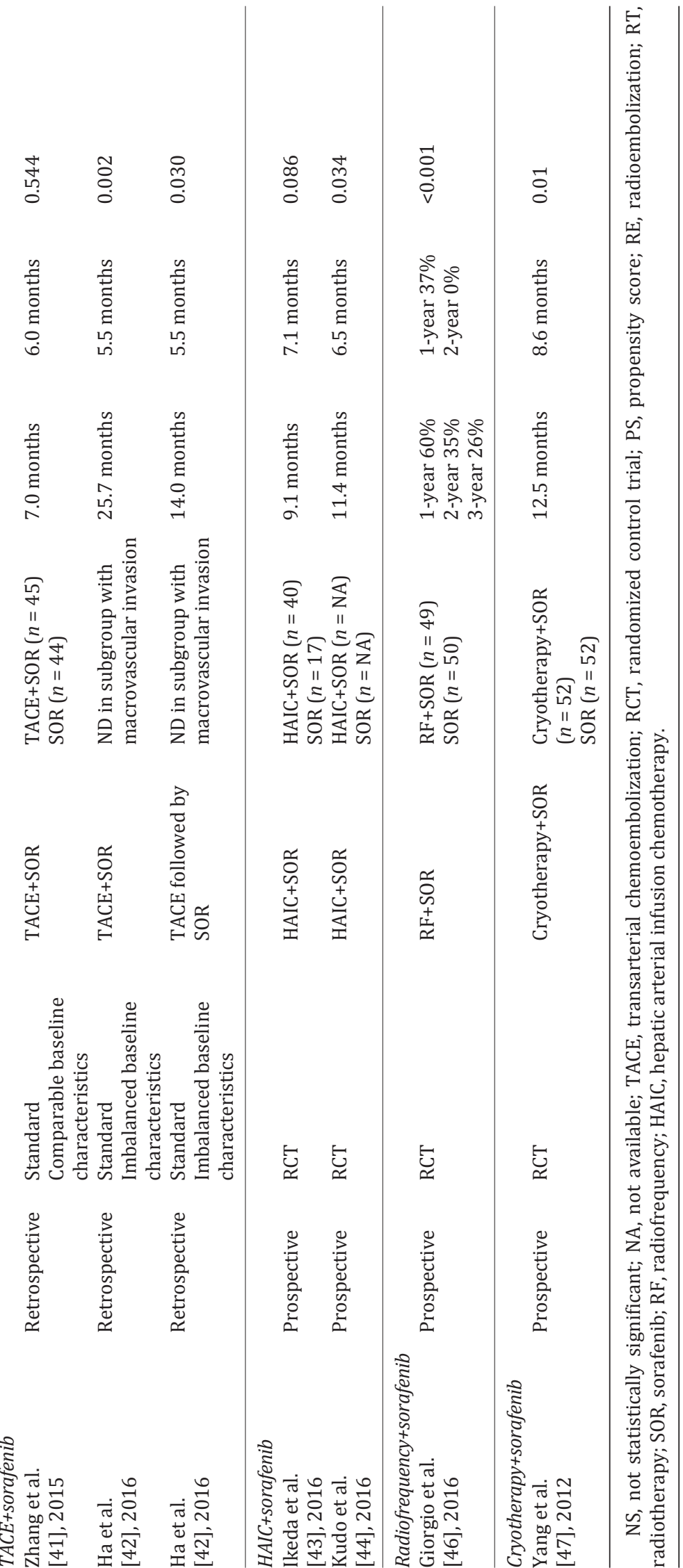


Costentin et al.: Hepatocellular Carcinoma with Macrovascular Invasion: Defining the

Optimal Treatment Strategy

Table 2. Ongoing clinical trials in patients with advanced hepatocellular carcinoma (HCC) according to inclusion criteria: macrovascular invasion (MVI) only (any phase) or with or without MVI (phase III)

\begin{tabular}{|c|c|c|c|c|}
\hline ClinicalTrials.gov identifier & Experimental treatment & Control arm & Phase & Setting \\
\hline \multicolumn{5}{|l|}{ HCC with MVI only } \\
\hline NCT03007212 & TACE & Sorafenib & IV & 1st line \\
\hline \multicolumn{5}{|l|}{ Radioembolization } \\
\hline NCT01556282 & TheraSphere & - & II & - \\
\hline NCT01887717 & TheraSphere & Sorafenib & III & 1st line \\
\hline \multicolumn{5}{|l|}{ External radiotherapy } \\
\hline NCT02571946 & Proton beam therapy & - & II & - \\
\hline \multicolumn{5}{|l|}{ Combination therapy } \\
\hline NCT01911000 & Radiotherapy and hyperthermia after TACE & - & II & 1st line \\
\hline NCT03009461 & Sorafenib and HAIC & Sorafenib & II & 1st line \\
\hline NCT02452853 & Hepatic resection and FOLFOX4 & - & II & 1st line \\
\hline NCT02301091 & TACE and RFA & TACE alone & III & - \\
\hline \multicolumn{5}{|l|}{ HCC with or without MVI } \\
\hline \multicolumn{5}{|l|}{ Combination therapy } \\
\hline NCT01126645 & SIRT+sorafenib (SORAMIC) & Sorafenib & III & 1st line \\
\hline NCT01556490 & SIRT+sorafenib (STOP HCC) & Sorafenib & III & 1st line \\
\hline NCT02562755 & Sorafenib+vaccinia virus-based immunotherapy & Sorafenib & III & 1st line \\
\hline NCT02774187 & Sorafenib+HAIC & Sorafenib & III & 1st line \\
\hline NCT01214343 & Sorafenib+low-dose cisplatin/fluorouracil HAIC & Sorafenib & III & 1st line \\
\hline NCT01829035 & Sorafenib+TACE & Sorafenib & III & 1st line \\
\hline NCT01730937 & Sorafenib+stereotactic body radiation therapy & Sorafenib & III & 1st line \\
\hline \multicolumn{5}{|l|}{ Antiangiogenic agents } \\
\hline NCT02435433 & Ramucirumab in patients with AFP $\geq 400 \mathrm{ng} / \mathrm{mL}$ & Placebo & III & 2nd line \\
\hline NCT02329860 & Apatinib & Placebo & III & 2nd line \\
\hline \multicolumn{5}{|c|}{ Cell-cycle inhibitors and antiproliferative agents } \\
\hline NCT01908426 & Cabozantinib & Placebo & III & 2nd line \\
\hline NCT01655693 & Doxorubicin transdrug (anthracyline) & $\begin{array}{l}\text { Controlled vs. best } \\
\text { supportive care }\end{array}$ & III & 2nd line \\
\hline \multicolumn{5}{|l|}{ Immune modulators } \\
\hline NCT02576509 & Nivolumab & Sorafenib & III & 1st line \\
\hline NCT02702401 & Pembrolizumab & Placebo & III & 2nd line \\
\hline
\end{tabular}

TACE, transarterial chemoembolization; HAIC, hepatic arterial infusion chemotherapy; RFA, radiofrequency ablation.

In addition, phase III trials in patients with advanced HCC with or without MVI will provide crucial information. Recently, the results of two trials comparing SIRT to sorafenib in advanced HCC (SARAH trial [NCT01482442] and the SIRveNIB trial [NCT NCT01135056]), have been released $[6,7]$. Both were designed to demonstrate superiority of SIRT over sorafenib, and failed to meet their primary endpoint: median overall survival was comparable between both treatment groups: 8.0 months with SIRT compared to 9.9 months with sorafenib in the SARAH trial $(p=0.179), 8.8$ months with SIRT compared to 10 months with sorafenib in the SIRveNIB trial $(p=0.36)$.

Some lessons need to be taken for future trials. Firstly, the SARAH and SIRveNIB trials hypothesized that SIRT alone could be superior to sorafenib. In both studies, response rate was significantly higher in the SIRT group (roughly $20 \%$ in the treated population) than in the sorafenib group (less than 12\%), suggesting that SIRT may be more likely to control the 
tumor in the liver. However, in this advanced clinical setting, extrahepatic spread can be undetected at the time of treatment initiation. Therefore, the lack of systemic treatment in the SIRT group might have prevented higher response rate to be translated into better overall survival, raising the question that a strategy combining local regional therapy (SIRT) and systemic treatment (sorafenib) may improve the outcome. The SORAMIC and STOP HCC trials will provide the answer to this question. In addition, further information on subgroup analyses, tumor targeting with SIRT (including or not including vascular invasion), and radiation dose delivered to the tumor are important variables to evaluate to improve both the SIRT process and patient selection. Indeed, Garin et al. [48] reported a significant correlation between overall survival and radiation dose (below vs. above $205 \mathrm{~Gy}$ ) and PVTT targeting (good vs. poor). Secondly and importantly, fewer severe adverse events were observed with SIRT when compared with those treated with sorafenib. This is very interesting considering the limited expected patient survival. Therefore, potential benefit of SIRT should be further explored and future trials should include extensive quality of life as well as cost-effectiveness assessments.

Alternatively, other locoregional therapies are currently being investigated in combination with sorafenib in phase III trials: HAIC plus sorafenib, TACE plus sorafenib, and stereotactic body radiation therapy plus sorafenib. Several new drugs are also investigated in the first- or second-line setting (Table 2).

After more than 10 years of negative trials testing systemic therapies in HCC, two trials testing antiangiogenic compounds recently met their primary endpoint. Regorafenib demonstrated superiority over placebo in second line after progression on sorafenib treatment [49]. Lenvatinib was shown to be noninferior to sorafenib in the first-line setting [50]. Therapeutic approaches targeting programmed cell death receptor 1 (PD-1) and its ligand, PD-L1, are emerging as potentially effective treatment for the management of HCC [51]. The CheckMate-040 study, a phase I/II trial, included 214 patients with histologically confirmed advanced HCC (sorafenib-naïve or experienced), treated with the PD-1 monoclonal antibody nivolumab. An objective response was observed in 42 patients $(20 \%$; $95 \%$ CI 15-26) who received nivolumab $3 \mathrm{mg} / \mathrm{kg}$ every 2 weeks in the dose-expansion phase. The 6- and 9-month survival rates were 83 and 74\%, respectively. In addition, several ongoing trials are evaluating PD-1 inhibitors in combination with other drugs targeting the immune system (NCT01658878) or radiation (NCT02837029). There is indeed a strong rationale to combine PD-1 inhibitors with radiation therapy [52]. It has also been demonstrated that programmed cell death-1 blockade enhances response to stereotactic radiation in an orthotopic murine model of HCC [53].

\section{Conclusion}

There is a growing body of evidence suggesting that alternative strategies to standardof-care sorafenib might improve survival in patients with advanced HCC with MVI but the level of evidence remains weak. Randomized phase III trials are ongoing and will hopefully provide information leading towards a more personalized treatment algorithm. The ideal strategy might be multimodal, using a combination of locoregional therapy and personalized systemic therapy.

\section{Acknowledgement}

Stephanie Linet Reyes, Alain Luciani. 
Costentin et al.: Hepatocellular Carcinoma with Macrovascular Invasion: Defining the Optimal Treatment Strategy

\section{Disclosure Statement}

Charlotte E. Costentin declares no conflicts of interest. Cristina R. Ferrone declares no conflicts of interest. Ronald S. Arellano declares no conflicts of interest. Suvranu Ganguli declares no conflicts of interest. Theodore S. Hong declares no conflicts of interest. Andrew X. Zhu declares advisory/consulting for BMS, Merck, Bayer, Novartis, Eisai, and Sanofi.

\section{References}

1 Cheung TK, Lai CL, Wong BC, Fung J, Yuen MF: Clinical features, biochemical parameters, and virological profiles of patients with hepatocellular carcinoma in Hong Kong. Aliment Pharmacol Ther 2006;24:573-583.

2 Llovet JM, Ricci S, Mazzaferro V, Hilgard P, Gane E, Blanc JF, de Oliveira AC, Santoro A, Raoul JL, Forner A, Schwartz M, Porta C, Zeuzem S, Bolondi L, Greten TF, Galle PR, Seitz JF, Borbath I, Häussinger D, Giannaris T, Shan M, Moscovici M, Voliotis D, Bruix J; SHARP Investigators Study Group: Sorafenib in advanced hepatocellular carcinoma. N Engl J Med 2008;359:378-390.

3 Heimbach J, Kulik LM, Finn R, Sirlin CB, Abecassis M, Roberts LR, Zhu A, Murad MH, Marrero J: AASLD guidelines for the treatment of hepatocellular carcinoma. Hepatology 2017, DOI: 10.1002/hep.29086.

4 European Association for the Study of the Liver, European Organisation for Research and Treatment of Cancer. EASL-EORTC clinical practice guidelines: management of hepatocellular carcinoma. J Hepatol 2012;56:908943.

5 Omata M, Lesmana LA, Tateishi R, Chen PJ, Lin SM, Yoshida H, Kudo M, Lee JM, Choi BI, Poon RT, Shiina S, Cheng AL, Jia JD, Obi S, Han KH, Jafri W, Chow P, Lim SG, Chawla YK, Budihusodo U, Gani RA, Lesmana CR, Putranto TA, Liaw YF, Sarin SK: Asian Pacific Association for the Study of the Liver consensus recommendations on hepatocellular carcinoma. Hepatol Int 2010;4:439-474.

6 Vilgrain V, Bouattour M, Sibert A, Lebtahi R, Ronot M, Pageaux G-P, Guiu B, Barraud H, Silvain C, Gérolami R, Oberti F, Raoul J-L, Costentin C, Samuel D, Dinut A, Pereira H, Chatellier G, Castera L; and the SARAH Trial Group: SARAH: a randomised controlled trial comparing efficacy and safety of selective internal radiation therapy (with yttrium-90 microspheres) and sorafenib in patients with locally advanced hepatocellular carcinoma. J Hepatol 2017;66:S63-S94.

7 Chow PHW, Gandhi M; Asia-Pacific Hepatocellular Carcinoma Trials Group: Phase III multi-centre open-label randomized controlled trial of selective internal radiation therapy (SIRT) versus sorafenib in locally advanced hepatocellular carcinoma: The SIRveNIB study. J Clin Oncol 2017;35(suppl; abstr 4002).

8 Cabibbo G, Enea M, Attanasio M, Bruix J, Craxì A, Cammà C: A meta-analysis of survival rates of untreated patients in randomized clinical trials of hepatocellular carcinoma. Hepatology 2010;51:1274-1283.

9 Kokudo T, Hasegawa K, Matsuyama Y, Takayama T, Izumi N, Kadoya M, Kudo M, Ku Y, Sakamoto M, Nakashima 0, Kaneko S, Kokudo N; Liver Cancer Study Group of Japan: Survival benefit of liver resection for hepatocellular carcinoma associated with portal vein invasion. Liver Cancer Study Group of Japan. J Hepatol 2016;65: 938-943.

10 Kokudo T, Hasegawa K, Yamamoto S, Shindoh J, Takemura N, Aoki T, Sakamoto Y, Makuuchi M, Sugawara Y, Kokudo N: Surgical treatment of hepatocellular carcinoma associated with hepatic vein tumor thrombosis. J Hepatol 2014;61:583-588.

11 www.acr.org/Quality-Safety/Ressources/LIRADS/LIRADS-v2014.

12 Rossi S, Ghittoni G, Ravetta V, Torello Viera F, Rosa L, Serassi M, Scabini M, Vercelli A, Tinelli C, Dal Bello B, Burns PN, Calliada F: Contrast-enhanced ultrasonography and spiral computed tomography in the detection and characterization of portal vein thrombosis complicating hepatocellular carcinoma. Eur Radiol 2008;18: 1749-1756.

13 Hu S, Zhang J, Cheng C, Liu Q, Sun G, Zuo C: The role of 18F-FDG PET/CT in differentiating malignant from benign portal vein thrombosis. Abdom Imaging 2014;39:1221-1227.

14 Vilana R, Bru C, Bruix J, Castells A, Sole M, Rodes J: Fine-needle aspiration biopsy of portal vein thrombus: value in detecting malignant thrombosis. Bru Am J Roentgenol 1993;160:1285-1287.

15 Ikai I, Kudo M, Arii S, Omata M, Kojiro M, Sakamoto M, Takayasu K, Hayashi N, Makuuchi M, Matsuyama Y, Monden M: Report of the 18th follow-up survey of primary liver cancer in Japan. Hepatol Res 2010;40:10431059.

16 Kudo M, Izumi N, Kokudo N, Matsui O, Sakamoto M, Nakashima O, Kojiro M, Makuuchi M; HCC Expert Panel of Japan Society of Hepatology: Management of hepatocellular carcinoma in Japan: consensus-based clinical practice guidelines proposed by the Japan Society of Hepatology (JSH) 2010 updated version. Dig Dis 2011; 29:339-364.

17 https://www.nccn.org.

18 Cheng AL, Kang YK, Chen Z, Tsao CJ, Qin S, Kim JS, Luo R, Feng J, Ye S, Yang TS, Xu J, Sun Y, Liang H, Liu J, Wang J, Tak WY, Pan H, Burock K, Zou J, Voliotis D, Guan Z: Efficacy and safety of sorafenib in patients in the AsiaPacific region with advanced hepatocellular carcinoma: a phase III randomised, double-blind, placebocontrolled trial. Lancet Oncol 2009;10:25-34. 
Costentin et al.: Hepatocellular Carcinoma with Macrovascular Invasion: Defining the

Optimal Treatment Strategy

19 Bruix J, Raoul JL, Sherman M, Mazzaferro V, Bolondi L, Craxi A, Galle PR, Santoro A, Beaugrand M, Sangiovanni A, Porta C, Gerken G, Marrero JA, Nadel A, Shan M, Moscovici M, Voliotis D, Llovet JM: Efficacy and safety of sorafenib in patients with advanced hepatocellular carcinoma: subanalyses of a phase III trial. J Hepatol 2012; 57:821-829.

20 Cheng AL, Guan Z, Chen Z, Tsao CJ, Qin S, Kim JS, Yang TS, Tak WY, Pan H, Yu S, Xu J, Fang F, Zou J, Lentini G, Voliotis D, Kang YK: Efficacy and safety of Sorafenib in patients with advanced hepatocellular carcinoma according to baseline status. Eur J of Cancer 2012;48:1452-1465.

21 Zhong JH, Rodriguez AC, Ke Y, Wang YY, Wang L, Li LQ: Hepatic resection as a safe and effective treatment for hepatocellular carcinoma involving a single large tumor, multiple tumors, or macrovascular invasion. Medicine (Baltimore) 2015;94:e396.

22 Wang HL, Cucchetti A, Zhong JH, Ye XP, Gu JH, Ma L, Peng NF, Li LQ: Should hepatic resection be recommended to patients with hepatocellular carcinoma and portal vein invasion? J Hepatol 2016;65:1057-1058.

23 Costentin CE, Decaens T, Laurent A, Nault JC, Paule B, Letoublon C, Luciani A, Calderaro J, Adam R, Bricault I, Amaddeo G, Cherqui D, Mallat A, Samuel D, Duvoux C, Ganne-Carrié N, Roudot-Thoraval F, Vibert E: Sorafenib versus surgical resection for hepatocellular carcinoma with macrovascular invasion: a propensity score analysis. Liver Int 2017, DOI: 10.1111/liv.13491.

24 Kim GA, Shim JH, Yoon SM, Jung J, Kim JH, Ryu MH, Ryoo BY, Kang YK, Lee D, Kim KM, Lim YS, Lee HC, Chung YH, Lee YS: Comparison of chemoembolization with and without radiation therapy and sorafenib for advanced hepatocellular carcinoma with portal vein tumor thrombosis: a propensity score analysis. J Vasc Interv Radiol 2015;26:320-329.

25 Nouso K, Miyahara K, Uchida D, Kuwaki K, Izumi N, Omata M, Ichida T, Kudo M, Ku Y, Kokudo N, Sakamoto M, Nakashima O, Takayama T, Matsui O, Matsuyama Y, Yamamoto K; Liver Cancer Study Group of Japan: Effect of hepatic arterial infusion chemotherapy of 5-fluorouracil and cisplatin for advanced hepatocellular carcinoma in the Nationwide Survey of Primary Liver Cancer in Japan. Br J Cancer 2013;109:1904-1907.

26 Song DS, Song MJ, Bae SH, Chung WJ, Jang JY, Kim YS, Lee SH, Park JY, Yim HJ, Cho SB, Park SY, Yang JM: A comparative study between sorafenib and hepatic arterial infusion chemotherapy for advanced hepatocellular carcinoma with portal vein tumor thrombosis. J Gastroenterol 2015;50:445-454.

27 Fukubayashi K, Tanaka M, Izumi K, Watanabe T, Fujie S, Kawasaki T, Yoshimaru Y, Tateyama M, Setoyama H, Naoe H, Kikuchi K, Sasaki Y: Evaluation of sorafenib treatment and hepatic arterial infusion chemotherapy for advanced hepatocellular carcinoma: a comparative study using the propensity score matching method. Cancer Med 2015;4:1214-1223.

28 Shiozawa K, Watanabe M, Ikehara T, Kogame M, Matsui T, Okano N, Kikuchi Y, Nagai H, Ishii K, Makino H, Igarashi Y, Sumino Y: Comparison of sorafenib and hepatic arterial infusion chemotherapy for advanced hepatocellular carcinoma: a propensity score matching study. Hepatogastroenterology 2014;61:885-891.

29 Huang YJ, Hsu HC, Wang CY, Wang CJ, Chen HC, Huang EY, Fang FM, Lu SN: The treatment responses in cases of radiation therapy to portal vein thrombosis in advanced hepatocellular carcinoma. Int J Radiat Oncol Biol Phys 2009;73:1155-1163.

30 Nakazawa T, Hidaka H, Shibuya A, Okuwaki Y, Tanaka Y, Takada J, Minamino T, Watanabe M, Kokubu S, Koizumi W: Overall survival in response to sorafenib versus radiotherapy in unresectable hepatocellular carcinoma with major portal vein tumor thrombosis: propensity score analysis. BMC Gastroenterol 2014;14: 84.

31 Bujold A, Massey CA, Kim JJ, Brierley J, Cho C, Wong RK, Dinniwell RE, Kassam Z, Ringash J, Cummings B, Sykes J, Sherman M, Knox JJ, Dawson LA: Sequential phase I and II trials of stereotactic body radiotherapy for locally advanced hepatocellular carcinoma. J Clin Oncol 2013;31:1631-1639.

32 Sugahara S, Nakayama H, Fukuda K, Mizumoto M, Tokita M, Abei M, Shoda J, Matsuzaki Y, Thono E, Tsuboi K, Tokuuye K: Proton-beam therapy for hepatocellular carcinoma associated with portal vein tumor thrombosis. Strahlenther Onkol 2009;185:782-788.

33 Hong TS, Wo JY, Yeap BY, Ben-Josef E, McDonnell EI, Blaszkowsky LS, Kwak EL, Allen JN, Clark JW, Goyal L, Murphy JE, Javle MM, Wolfgang JA, Drapek LC, Arellano RS, Mamon HJ, Mullen JT, Yoon SS, Tanabe KK, Ferrone CR, Ryan DP, DeLaney TF, Crane CH, Zhu AX: Multi-institutional phase II study of high-dose hypofractionated proton beam therapy in patients with localized, unresectable hepatocellular carcinoma and intrahepatic cholangiocarcinoma. J Clin Oncol 2016;34:460-468.

34 Sangro B, Iñarrairaegui M, Bilbao JI: Radioembolization for hepatocellular carcinoma. J Hepatol 2012;56:464473.

35 Cho YY, Lee M, Kim HC, Chung JW, Kim YH, Gwak GY, Bae SH, Kim do Y, Heo J, Kim YJ: Radioembolization is a safe and effective treatment for hepatocellular carcinoma with portal vein thrombosis: a propensity score analysis. PLoS One 2016;11:e0154986.

36 de la Torre MA, Buades-Mateu J, de la Rosa PA, Lué A, Bustamante FJ, Serrano MT, Testillano M, Lorente S, Arenas JI, Gil C, Iñarrairaegui M, Sangro B: A comparison of survival in patients with hepatocellular carcinoma and portal vein invasion treated by radioembolization or sorafenib. Liver Int 2016;36:1206-1212.

37 Edeline J, Crouzet L, Campillo-Gimenez B, Rolland Y, Pracht M, Guillygomarc'h A, Boudjema K, Lenoir L, Adhoute X, Rohou T, Boucher E, Clément B, Blanc JF, Garin E: Selective internal radiation therapy compared with sorafenib for hepatocellular carcinoma with portal vein thrombosis. Eur J Nucl Med Mol Imaging 2016; 43:635-643. 
Costentin et al.: Hepatocellular Carcinoma with Macrovascular Invasion: Defining the

Optimal Treatment Strategy

38 Giorgio A, Di Sarno A, de Stefano G, Farella N, Scognamiglio U, de Stefano M, Giorgio V: Hepatocellular carcinoma with cirrhosis: are patients with neoplastic main portal vein invasion eligible for percutaneous radiofrequency ablation of both the nodule and the portal venous tumor thrombus? AJR Am J Roentgenol 2009;193: 948-954.

39 Lu ZH, Shen F, Yan ZL, Li J, Yang JH, Zong M, Shi LH, Wu MC: Treatment of portal vein tumor thrombus of hepatocellular carcinoma with percutaneous laser ablation. J Cancer Res Clin Oncol 2009;135:783-789.

40 Sakamoto K, Nagano H: Surgical treatment for advanced hepatocellular carcinoma with portal vein tumor thrombus. Hepatol Res 2017;47:957-962.

41 Zhang Y, Fan W, Wang Y, Lu L, Fu S, Yang J, Huang Y, Yao W, Li J: Sorafenib with and without transarteria chemoembolization for advanced hepatocellular carcinoma with main portal vein tumor thrombosis: a retrospective analysis. Oncologist 2015;20:1417-1424.

42 Ha Y, Lee D, Shim JH, Lim YS, Lee HC, Chung YH, Lee YS, Park SR, Ryu MH, Ryoo BY, Kang YK, Kim KM: Role of transarterial chemoembolization in relation with sorafenib for patients with advanced hepatocellular carcinoma. Oncotarget 2016;7:74303-74313.

43 Ikeda M, Shimizu S, Sato T, Morimoto M, Kojima Y, Inaba Y, Hagihara A, Kudo M, Nakamori S, Kaneko S, Sugimoto R, Tahara T, Ohmura T, Yasui K, Sato K, Ishii H, Furuse J, Okusaka T: Sorafenib plus hepatic arterial infusion chemotherapy with cisplatin versus sorafenib for advanced hepatocellular carcinoma: randomized phase II trial. Ann Oncol 2016;27:2090-2096.

44 Kudo M, Ueshima K, Yokosuka O, Obi S, Izumi N, Aikata H, Nagano H, Hatano E, Sasaki Y, Hino K, Kumada T, Yamamoto K, Imai Y, Iwadou S, Ogawa C, Okusada T, Arai Y, Kanai F; AkazawaK and Silius Study Group: Prospective randomized controlled phase III trial comparing the efficacy of sorafenib versus sorafenib in combination with low-dose cisplatin/fluorouracil hepatic arterial infusion chemotherapy in patients with advanced hepatocellular carcinoma. J Hepatol 2016;64(issue 2, suppl):S183-S212.

45 Cho JY, Paik YH, Park HC, Yu JI, Sohn W, Gwak GY, Choi MS, Lee JH, Koh KC, Paik SW, Yoo BC: The feasibility of combined transcatheter arterial chemoembolization and radiotherapy for advanced hepatocellular carcinoma. Liver Int 2014;34:795-801.

46 Giorgio A, Merola MG, Montesarchio L, Merola F, Santoro B, Coppola C, Gatti P, Amendola F, DI Sarno A, Calvanese A, Matteucci P, Giorgio V: Sorafenib combined with radio-frequency ablation compared with sorafenib alone in treatment of hepatocellular carcinoma invading portal vein: a Western randomized controlled trial. Anticancer Res 2016;36:6179-6183.

47 Yang Y, Lu Y, Wang C, Bai W, Qu J, Chen Y, Chang X, An L, Zhou L, Zeng Z, Lou M, Lv J: Cryotherapy is associated with improved clinical outcomes of Sorafenib therapy for advanced hepatocellular carcinoma. Cell Biochem Biophys 2012;63:159-169.

48 Garin E, Rolland Y, Edeline J, Icard N, Lenoir L, Laffont S, Mesbah H, Breton M, Sulpice L, Boudjema K, Rohou T, Raoul JL, Clement B, Boucher E: Personalized dosimetry with intensification using 90Y-loaded glass microsphere radioembolization induces prolonged overall survival in hepatocellular carcinomapatients with portal vein thrombosis. J Nucl Med 2015;56:339-346.

49 Bruix J, Qin S, Merle P, Granito A, Huang YH, Bodoky G, Pracht M, Yokosuka O, Rosmorduc O, Breder V, Gerolami R, Masi G, Ross PJ, Song T, Bronowicki JP, Ollivier-Hourmand I, Kudo M, Cheng AL, Llovet JM, Finn RS, LeBerre MA, Baumhauer A, Meinhardt G, Han G; RESORCE Investigators: Regorafenib for patients with hepatocellular carcinoma who progressed on sorafenib treatment (RESORCE): a randomised, double-blind, placebocontrolled, phase 3 trial. Lancet 2017;389:56-66.

50 Cheng AL, Finn RS, Qin S, Han KH, Ikeda K, Piscaglia F, Baron AD, Park JW, Han G, Jassem J, Blanc JF, Vogel A, Komov D, Evans TRJ, López-López C, Dutcus CE, Ren M, Kraljevic S, Tamai T, Kudo M: Phase III trial of lenvatinib (LEN) vs sorafenib (SOR) in first-line treatment of patients (pts) with unresectable hepatocellular carcinoma (uHCC). J Clin Oncol 2017;35(suppl; abstr 4001).

51 El-Khoueiry AB, Sangro B, Yau T, Crocenzi TS, Kudo M, Hsu C, Kim TY, Choo SP, Trojan J, Welling TH Rd, Meyer T, Kang YK, Yeo W, Chopra A, Anderson J, Dela Cruz C, Lang L, Neely J, Tang H, Dastani HB, Melero I: Nivolumab in patients with advanced hepatocellular carcinoma (CheckMate 040): an open-label, non-comparative, phase 1/2 dose escalation and expansion trial. Lancet 2017;389:2492-2502.

52 Okuma K, Yamashita H, Niibe Y, Hayakawa K, Nakagawa K: Abscopal effect of radiation on lung metastases of hepatocellular carcinoma: a case report. J Med Case Rep 2011;5:111.

53 Friedman D, Baird JR, Young KH, Cottam B, Crittenden MR, Friedman S, Gough MJ, Newell P: Programmed cell death-1 blockade enhances response to stereotactic radiation in an orthotopic murine model of hepatocellular carcinoma. Hepatol Res 2017;47:702-714. 